\title{
Vitamin D and its Role in the Management and Prevention of Lower Respiratory Tract Infections in Infants and Young Children
}

\author{
John M PetTIFor \\ From SAMRC-Wits Developmental Pathways for Health Research Unit, Department of Paediatrics, Faculty of Health Sciences, \\ University of the Witwatersrand, Johannesburg, South Africa.john.pettifor@wits.ac.za
}

$\mathrm{L}$ ower respiratory tract infections are a major cause of mortality in children below the age of five years, particularly in resource-poor countries. Although advances in treatment protocols have reduced mortality rates, and improved vaccine technology has seen the development of more effective vaccines against a number of pathogens such as Streptococcus pneumoniae, the costs involved may prohibit their introduction in those countries most in need. Thus cheaper alternatives to boost infants' and young children's resistance to respiratory infections, and to reduce the severity of the disease when it occurs, are urgently needed. Over the last 20 years, the role of vitamin $\mathrm{D}$ in modulating the immune response to infection has generated considerable interest. The ability of vitamin D to enhance innate immunity through its role in stimulating the production of a number of antibacterial proteins, such as cathelicidin and defensins, and autophagosomes by activated monocytes and macrophages is well documented [1]. Vitamin D also has a role in adaptive immunity reducing the acute inflammatory response and increasing Th2 lymphocytes. A number of studies have highlighted the association between vitamin $\mathrm{D}$ deficiency/rickets and acute lower respiratory tract infections/pneumonia $[2,3]$; and in casecontrol studies, $25(\mathrm{OH}) \mathrm{D}$ levels have been found to be lower in cases with respiratory infections than controls [4], but it is unclear if improving the vitamin D status of infants will reduce the severity of the disease. Although it is possible that the observed association between rickets and pneumonia reflects the impaired immune response accompanying vitamin D deficiency, it is also possible that mechanical factors such as more pliable ribs associated with rickets and reduced ventilation and clearance of lung secretions due to hypotonia might play major roles.

In a randomized controlled trial published in this issue of Indian Pediatrics, Gupta and colleagues [5] were unable to show a convincing evidence of positive biological effects of vitamin D supplementation on either the response of severe pneumonia to treatment or the prevention of recurrence over a six month period in under-five children. Before one discards a possible positive effect of vitamin $\mathrm{D}$ status on the response to therapy for severe pneumonia in young children, it must be appreciated that in the present study vitamin $\mathrm{D}$ supplementation only began at the time of the child's hospitalization with pneumonia; thus there was little time for supplementation to have an effect on vitamin D status and thus on the enhancement of the speed of resolution of the pneumonia. Few studies have assessed the pharmacokinetics of a bolus of vitamin D in young children. Thacher and colleagues [6] studied the change in serum $25(\mathrm{OH}) \mathrm{D}$ in groups of young Nigerian children following an oral bolus of 50,000 IU vitamin D2 or D3. Peak concentrations of $25(\mathrm{OH}) \mathrm{D}$ were found 3 days after bolus administration, which is longer than the time taken for resolution of the clinical features of severe pneumonia (median approximately 30 hours). The findings of Gupta, et al. [5] are in keeping with two other studies which reported a lack of a therapeutic effect of acute vitamin D supplementation on the rate of resolution of acute pneumonia [7]. The second aspect of the study by Gupta, et al. [5] was to assess the effect of vitamin D supplementation on the incidence of recurrence of pneumonia over six months. Once again, no effect was noted, but it is possible that the bolus of vitamin D was not given frequently enough to maintain vitamin $\mathrm{D}$ sufficiency, as the difference in $25(\mathrm{OH}) \mathrm{D}$ in the treatment group between admission and 3 months had fallen to only $7 \mathrm{ng} / \mathrm{mL}$ compared to $30 \mathrm{ng} / \mathrm{mL}$ at two weeks. $25(\mathrm{OH}) \mathrm{D}$ concentrations were not measured at 6 months after administration, but it is likely that the placebo and study groups would have had very similar levels. As mentioned by Gupta, et al. [5], these results are at variance with those reported from Kabul [8], where recurrence of pneumonia was reduced for three months following administration of $100,000 \mathrm{IU}$ vitamin D. It is of interest to note that the same authors in another study conducted in 
Kabul were unable to show an effect of chronic vitamin D supplementation (100,000 IU vitamin D three monthly) on the incidence of the first episode of pneumonia in infants and young children [9].

Some studies suggest that current vitamin D status as well as in utero vitamin $\mathrm{D}$ exposure may be inversely associated with the incidence of asthma, wheeze and respiratory infections in young children. A recent metaanalysis of 16 birth-cohort studies concluded that increased in utero exposure to $25(\mathrm{OH}) \mathrm{D}$ reduced the risk of asthma and wheezing, but not of respiratory tract infections in children [10].

Thus, evidence for a beneficial effect of vitamin D supplementation on the incidence of lower respiratory tract infections remains inconclusive [11,12]. Until further supporting evidence is available, pediatricians and other child health professionals should increase their efforts to prevent vitamin D deficiency during pregnancy and eradicate rickets during infancy and childhood through ensuring adequate vitamin D status during pregnancy and universal vitamin $\mathrm{D}$ supplementation of infants less than 12 months of age, as is currently recommended in a global consensus statement [13].

Funding: None; Competing interest: None stated.

\section{REFERENCES}

1. Hewison M. Vitamin D and immune function: an overview. Proc Nutr Soc. 2012;71:50-61.

2. Muhe L, Luiseged S, Mason KE, Simoes EAF. Casecontrol study of the role of nutritional rickets in the risk of developing pneumonia in Ethiopian children. Lancet. 1997;349:1801-4.

3. Larkin A, Lassetter J. Vitamin D deficiency and acute lower respiratory infections in children younger than 5 years: identification and treatment. J Pediatr Health Care. 2014;28:572-82.
4. Velarde Lopez AA, Gerber JS, Leonard MB, Xie D, Schinnar R, Strom BL. Children with lower respiratory tract infections and serum 25-hydroxyvitamin D3 levels: A case-control study. Pediatr Pulmonol. 2016;51:1080-7.

5. Gupta P, Dewan P, Shah D, Sharma NL, Bedi N, Kuar IR, et al. Vitamin $\mathrm{D}$ supplementation for treatment and prevention of penumonia in under-five children: A randomized double-blind placebo controlled trial. Indian Pediatr. 2016;53:967-76.

6. Thacher TD, Fischer PR, Obadofin MO, Levine MA, Singh RJ, Pettifor JM. Comparison of metabolism of vitamins D2 and D3 in children with nutritional rickets. J Bone Miner Res. 2010;25:1988-95.

7. Das RR, Singh M, Panigrahi I, Naik SS. Vitamin D supplementation for the treatment of acute childhood pneumonia: a systematic review. ISRN Pediatr. 2013;2013:459160.

8. Manaseki-Holland S, Qader G, Isaq Masher M, Bruce J, Zulf Mughal M, Chandramohan D, et al. Effects of vitamin D supplementation to children diagnosed with pneumonia in Kabul: a randomised controlled trial. Trop Med Int Health. 2010;15:1148-55.

9. Manaseki-Holland S, Maroof Z, Bruce J, Mughal MZ, Masher MI, Bhutta ZA, et al. Effect on the incidence of pneumonia of vitamin D supplementation by quarterly bolus dose to infants in Kabul: a randomised controlled superiority trial. Lancet. 2012;379:1419-27.

10. Feng H, Xun P, Pike K, Wills AK, Chawes BL, Bisgaard H, et al. In utero exposure to $25(\mathrm{OH}) \mathrm{D}$ and risk of childhood asthma, wheeze and respiratory tract infections: a metaanalysis of birth cohort studies. J Allergy Clin Immunol. 2016 (in press)

11. Esposito S, Lelii M. Vitamin D and respiratory tract infections in childhood. BMC Infect Dis. 2015;15:487.

12. Ali SR, McDevitt H. Question 1: Does vitamin D supplementation prevent acute lower respiratory tract infections in children? Arch Dis Child. 2015;100:892-5.

13. Munns CF, Shaw N, Kiely M, Specker BL, Thacher TD, Ozono K, et al. Global Consensus Recommendations on prevention and management of nutritional rickets. J Clin Endocrinol Metab. 2016;101:394-415. 